\title{
RESEARCHES OF OPTIMUM LEAF AREA INDEX DYNAMIC MODELS FOR RAPE(BRASSICA NAPUS L.)
}

Hongxin $\mathrm{Cao}^{1, *}$, Chunlei Zhang ${ }^{2}$, Guangming $\mathrm{Li}^{2}$, Baojun Zhang ${ }^{3}$, Suolao Zhao $^{3}$, Baoqing Wang ${ }^{3}$, Zhiqing Jin $^{1}$, Dawei Zhu ${ }^{1}$, Juanjuan Zhu ${ }^{3}$, Xiufang Wei ${ }^{1}$

${ }^{1}$ Institute of Agricultural Resources and Environment Research/Engineering Research Center for Digital Agriculture, Jiangsu Academy of Agricultural Sciences, Nanjing 210014, Jiangsu Province, P.R.China

${ }^{2}$ Institute of Oil Crops Research, Chinese Academy of Agricultural Sciences, Wuhan 430062, Hubei Province, P.R.China

${ }^{3}$ Northwest Sci-Tech University of Agriculture and Forestry, Yangling 712100, Shaanxi Province, P.R.China

* Corresponding author, Address: Institute of Agricultural Resources and Environment Research/Engineering Research Center for Digital Agriculture, Jiangsu Academy of Agricultural Sciences, Nanjing 210014, Jiangsu Province, P.R.China, Tel: +86-2584390125, Fax:+86-25-84390248,Email: caohongxin@hotmail.com

Abstract: The objectives of developing optimum leaf area index dynamic models for rape (OLAIDM) was to develop Rape Cultivation Simulation-OptimizationDecision Making System(Rape-CSODS), to design its planting, to regulate and control its growth and development, and to fulfill its high yield, good quality, high benefits and standard production eventually. The OLAIDM were developed based on field experiments with 3 cultivars, 6 sowing dates, 2 types of plant pattern and 4 sites from 2002 to 2007 in middle and lower valley of Yangtze river in China and relative data from references of rape researches, employed ideas of R/WCSODS (Rice/Wheat Cultivation SimulationOptimization-Decision Making System), and in the same time, the OLAIMR and its parameters also were assessed, calibrated and tested. The average absolute deviation(de), correlation coefficients(r) and the standard errors of their absolute deviation(Sde) of between the observed and simulated values for LAI of two cultivars in Wuhan and Nanjing were -0.03 0.1533, $0.9707 \sim 0.9997$ and0.1332 0.4032, respectively. 1:1 line of them were in Fig. 1 to 4 . Multi-factors such as the ramification types, cultivars, and light et al. were taken into account in this study, therefore, the OLAIDM with general

Please use the following format when citing this chapter:

Cao, H., Zhang, C., Li, G., Zhang, B., Zhao, S., Wang, B., Jin, Z., Zhu, D., Zhu, J. and Wei, X., 2009, in IFIP International Federation for Information Processing, Volume 295, Computer and Computing Technologies in Agriculture II, Volume 3, eds. D. Li, Z. Chunjiang, (Boston: Springer), pp. 1585-1594. 
adaptability, clear yield aim, mechanism, and dynamic characteristic can simulate optimum LAI dynamic for rape under different sites, cultivars and ramification types, and yielding levels.

Key words: rape; optimum LAI dynamic; models

\section{INTRODUCTION}

Rape is one of four main oil crops in the world, whose plant area is about $14,100,000$ ha in general. In the same time, it also is main oil crops in China, and its plant area is from 4,000,000 to 5,000,000 ha.

The crop simulation and the technology of $3 \mathrm{~S}$ (GPS, GIS, and RS) are core and foundation of digital cultivation technique systems (Cao et al., 2005). The crop simulation technology mainly included the crop growth simulation, the optimum models in cultivation, and the simulationoptimization-decision making. The optimum models in rape cultivation mainly included models of the optimum season, population dynamic, seed rate, fertilizer rate, and soil water, etc., which ware foundation and goals of the simulation-optimization-decision making in rape, and had an important significant in promoting digital cultivation and realizing management with objective, dynamic, quantitative and optimum.

In the world, the researches of rape models can be divided into two stages obviously, i.e. experiential models as main (70-80's of 20 century) and mechanism models as main (since 90's of 20 century). In the later stages, rape growth and development and ecological system models such as EPR95, DAR95, LINTUL-BRASNAP, CERES, APSIM-Canola, and CECOL etc. were developed by Kiniry et al., Peterson et al., Habekotté, Gabrielle et al., Robertson et al., Husson et al.(Kiniry et al.,1995; Peterson et al.,1995; Habekotté, 1997; Gabrielle et al.,1998; Robertson et al.,1997; Husson et al.,1997), respectively, and they can simulate in real time. However, in China, the researches of rape simulation model were not more, and Liu Hong et al.(Liu et al., 2004), Liu Qiemei et al.(Liu et al.,2004) set up simulation model of rape phenophase etc.. Cao Hongxin et al.(Cao et al.,2006) carried out the studies of simulation models of phenophase, leaf age, dry matter, leaf area, and ramification numbers.

The objectives of this study were to establish the OLAIDM based on field experiments in Yangtz river middle and lower valley of China. 


\section{MATERIALS AND METHEODS}

\subsection{Research Methods}

\subsection{Referring to references}

The aims were to apprehend and master rape growth and development rules and principles of growth regulation and control for rape whole, to obtain initial parameters on varieties, soil, climates etc., through referring to the references on papers and books of rape physiology, ecology, cultivation etc.

\subsection{Development models}

The optimization models of rape cultivation were established based on referring to references and apprehending rape growth and development rules fully, in terms of rape physiology and ecology principles and optimization principles of rape cultivation.

\section{$2.4 \quad$ Experiments}

In order to decide the parameters of the models and verify the models, the field experiments in multi-sites and multi-years were carried out adopting different rape cultivar types.

Experiment 1: Two rape genotypes "No.9 Zhongshuang"(conventional) and "No.2 Zhongyouza"(hybrid) were grown in the field from 2002 to 2005 on Red loam soil near Wuhan(The total nitrogen was at $0.12 \%$, organic matter at $2.07 \%, \mathrm{pH} 7.79$, and volume weight at $1.50 \mathrm{~g} / \mathrm{cm}^{3}$ in pre-planting in soil), Hubei Province, respectively. The six planting dates included the first planting date on 15 September, the other planting date every 7 days each year. 12 treatments, 3 replications, and 36 plots with $8 \mathrm{~m}$ long, $2.5 \mathrm{~m}$ width were included in the experiments. The plots were arranged random. The varieties were breed by Institute of Oil Crops Research, China Academy of Agricultural Sciences (CAAS). Fertilizing and other field management in plots were the same. Nitrogen at $180 \mathrm{~kg}$ ha-1, phosphorus at $120 \mathrm{~kg}$ ha-1, potassium at $180 \mathrm{~kg}$ ha-1, and boron at $15 \mathrm{~kg}$ ha-1 were incorporated.

Experiment 2: The rape genotypes "No.16 Ningyou" was grown in the field from 2006 to 2007 on Yellow umber soil with higher fertility in preplanting in soil in Nanjing, Jiangsu Province. 2 treatments, 3 replications, and 6 plots with $3 \mathrm{~m}$ long, $2.5 \mathrm{~m}$ width were included in the experiments. The 
plots were arranged random. The varieties were breed by Institute of Economic Crops Research, Jiangsu Academy of Agricultural Sciences. Fertilizing and other field management in plots were the same.

Phenophase, LAI, the total shoot numbers, biomass, leaf age, leaf photosynthesis, plant characters, and meteorological and soil data etc. were observed during rape growth or after harvest.

\section{DEVELOPMENT OF MODELS}

The Optimum LAI(OLAI) was basis of forming the optimum pod area index (OPAI), if the OLAI had been gotten, the OPAI also was gotten(Liu,1987). In terms of definition of the optimum LAI, if light intensity of down part leaves of population just equal to compensating light intensity for photosynthesis, and the most biomass had been gained, the LAI of the population was the OLAI (Wang,1991).

\subsection{The optimum maxmum LAI (OMLAI) at early anthesis}

The OMLAI in whole life occurred generally from early anthesis to middle anthesis(Ling,2000). The essence of deciding the OMLAI at this stage were to realize the optimum accumulation of photosynthesis in 40 days around early anthesis. Therefore, according to Monsi equation, the OLAI in this phenophase $\left(\mathrm{L}_{\mathrm{AO}}\right)$ of rape can be expressed as follows:

$$
\mathrm{L}_{\mathrm{AO}}=-\left(1 / \mathrm{E}_{\mathrm{A}}\right) \ln \left(\mathrm{B} \cdot \mathrm{I}_{\mathrm{bA}} / \mathrm{I}_{0 \mathrm{~A}}\right)
$$

The parameter $\mathrm{B}$ can be gained using the definition of light compensating point for rape and relationships between photosynthesis rate and light intensity of single leaf, i.e., the relationships among the gross photosynthesis $\operatorname{rate}\left(\mathrm{D}_{\mathrm{GP}}\right)$, the respiration $\operatorname{rate}\left(\mathrm{D}_{\mathrm{R}}\right)$ and the net photosynthesis rate $\left(\mathrm{D}_{\mathrm{NP}}\right)$ of rape in all day can be expressed as follows. When equation (2) was satisfied, the LAI closed to the optimum.

$$
\mathrm{D}_{\mathrm{GP}}=\mathrm{D}_{\mathrm{R}} \text { 或 } \mathrm{D}_{\mathrm{NP}}=\mathrm{D}_{\mathrm{GP}}-\mathrm{D}_{\mathrm{LR}}=\mathrm{D}_{\mathrm{DR}}
$$

When light intensity(I) was enough small, photosynthesis rate for rape equals to $b \cdot I$, the $D_{\mathrm{NP}}$ can be computed as follows(wang, 1991).

$$
\begin{aligned}
& D_{\mathrm{NP}}=\mathrm{D}_{\mathrm{L}} \cdot \mathrm{b} \cdot \mathrm{I}_{\mathrm{C}} \cdot \mathrm{B} \\
& \mathrm{D}_{\mathrm{DR}}=\mathrm{D}_{\mathrm{AYR}}+\mathrm{N}_{\mathrm{IR}}
\end{aligned}
$$




$$
\begin{aligned}
& \mathrm{D}_{\mathrm{AYR}}=\mathrm{D}_{\mathrm{L}} \cdot \mathrm{b} \cdot \mathrm{I}_{\mathrm{C}} \\
& \mathrm{N}_{\mathrm{IR}}=\left(24-\mathrm{D}_{\mathrm{L}}\right) \cdot \mathrm{m} \cdot \mathrm{b} \cdot \mathrm{I}_{\mathrm{C}} \\
& \mathrm{m}=\mathrm{Q}_{10}{ }^{-\mathrm{TR} / 20} \\
& \mathrm{~B}=\left(\left(24-\mathrm{D}_{\mathrm{L}}\right) \cdot \mathrm{m}+\mathrm{D}_{\mathrm{L}}\right) / \mathrm{D}_{\mathrm{L}}
\end{aligned}
$$

where $\mathrm{I}_{0 \mathrm{~A}}$ is the horizontal nature light intensity above the population at this phenophase in the local, which equals to product of daily average solar radiation by coefficient $(C)$. $\left(B \cdot I_{b A}\right)$ is the light intensity of basic part of population at this phenophase. $\mathrm{E}_{\mathrm{A}}$ is the extinction coefficient of population in this phenophase. $\mathrm{I}_{\mathrm{bA}}$ is the compensating light intensity of basic part of population at this phenophase. $\mathrm{D}_{\mathrm{LR}}$ and $\mathrm{D}_{\mathrm{DR}}$ are the photo respiration rate and dark respiration rate, respectively. $D_{L}$ is the daily sunlight length $(h) . b$ is the parameter of photosynthesis for rape. $\mathrm{I}_{\mathrm{C}}$ is the instantaneous compensating light intensity for rape leaf. $b \cdot I_{C}$ is the hourly net photosynthesis rate at light compensating point. $\mathrm{D}_{\mathrm{AYR}}$ and $\mathrm{N}_{\mathrm{IR}}$ are the day and night respiration rate for rape. $\left(24-D_{L}\right)$ is the dark length(h). $m$ represents the ratio of day respiration rate to night respiration rate resulted by difference in temperature between day and night, and $T_{R}$ represents daily difference between the maximum temperature and the minimum temperature. $\mathrm{Q}_{10}$ is temperature coefficient of respiration for rape, which equals to 2.0(Wang,1991). The formula (1) showed that the OLAI for rape at early anthesis can be decided by the following factors: (a) the total radiation in 40 days around early anthesis, (b) the local average day length around early anthesis, (c) the local average daily difference between the maximum temperature and the minimum temperature around early anthesis, (d) light compensation point of rape cultivars, and (e) the plant types of cultivars and extinction coefficient, etc.(responsible to yielding levels) .

\subsection{The OLAI at enlongation}

The principle of estimating the OLAI at this phenophase was that middle and down part of population had some extent light distribution when this phenophase was occurring the OLAI. Therefore, the OLAI at this phenophase, $\mathrm{L}_{\mathrm{EO}}$, can expressed as follows.

$$
\mathrm{L}_{\mathrm{EO}}=-1 / \mathrm{E}_{\mathrm{E}} \cdot \ln \left(\mathrm{B} \cdot \mathrm{I}_{\mathrm{bE}} / \mathrm{I}_{0 \mathrm{E}}\right)
$$

where $E_{E}$ is extinction coefficient of population at this phenophase, $I_{b E}$ light compensation point of basic part of population at this phenophase and $\mathrm{I}_{\mathrm{OE}}$ horizontal nature light intensity above the population at this phenophase 
in the local. The formula (9) showed that the OLAI for rape at enlongation can be decided by the following factors: (a) the plant types of cultivars and extinction coefficient, (b) the local total solar radiation at this phenophase, and (c) plant density, etc.

\subsection{The OLAI at ten leaves(LTO) and reviving(LPO)}

They can be computed as follows, respectively.

$$
\begin{aligned}
& \mathrm{L}_{\mathrm{TO}}=\mathrm{B}_{\mathrm{SO}} \cdot \mathrm{L}_{\mathrm{TS}} / 10000 \\
& \mathrm{~L}_{\mathrm{PO}}=\mathrm{B}_{\mathrm{SO}} \cdot \mathrm{L}_{\mathrm{PS}} / 10000
\end{aligned}
$$

where $\mathrm{B}_{\mathrm{SO}}$ is the optimum plant numbers $\left(10^{4} \cdot \mathrm{hm}^{-2}\right)$, and $\mathrm{L}_{\mathrm{TS}}$ and $\mathrm{L}_{\mathrm{PS}}$ represent the average leaf area per plant (main stem leaf) at ten leaves and reviving, respectively. The formula (10) and (11) showed that the optimum LAI for rape at the phenophase can be decided by the following factors: (a) the optimum basic seedling number, the stem and the first ramification number, and the available stem and ramification number, which dealt with yielding levels, and (b) the average leaf area per plant at ten leaves and reviving, which dealt with yielding levels and growth types of rape.

\subsection{The OLAI at end anthesis (LDO)}

It generally was around $25 \%$ that of early anthesis according to experiment and reference (Ling,2000). Therefore, it can be computed as follows:

$$
\mathrm{L}_{\mathrm{DO}}=\mathrm{b}_{\mathrm{A}} \mathrm{L}_{\mathrm{AO}}
$$

where $b_{A}$ represents percent of the OLAI at end anthesis accounting for that of at early anthesis in a yielding level.

\section{PARAMETER ASSESSING AND CASES OF MODEL VERIFYING}

\subsection{Parameter Assessing}

The conversion coefficient, $\mathrm{C}=5007.6 \mu \mathrm{mol} \cdot \mathrm{S}^{-1} \cdot \mathrm{m}^{-2}$ (corresponding to $\left.1 \mathrm{MJ} \cdot \mathrm{m}^{2} \cdot \mathrm{h}^{-1}\right)$. 
The population extinction coefficient: Through mensuration of light distribution and reverse deducing, the extinction coefficient of population at the enlongation, $\mathrm{E}_{\mathrm{E}}$ was 0.68 , and the extinction coefficient of population at the early anthesis, $\mathrm{E}_{\mathrm{A}}$ was 0.48 at $2400 \mathrm{~kg} / \mathrm{hm}^{2}$ yield planted in Wuhan area; the extinction coefficient of population at the enlongation, $\mathrm{E}_{\mathrm{E}}$ was 0.55 , and the extinction coefficient of population at the early anthesis, $\mathrm{E}_{\mathrm{A}}$ was 0.55 at $2550 \mathrm{~kg} / \mathrm{hm}^{2}$ yield planted in Nanjing area.

The light compensate points of population basis part: $\left(\mathrm{B} \cdot \mathrm{I}_{\mathrm{CE}}\right)$ was $30.943 \mu \mathrm{mol} \cdot \mathrm{S}^{-1} \cdot \mathrm{m}^{-2}$ at the enlongation, and $\mathrm{I}_{\mathrm{CH}}$ was $6.872 \mu \mathrm{mol} \cdot \mathrm{S}^{-1} \cdot \mathrm{m}^{-2}$ at $2400 \mathrm{~kg} / \mathrm{hm}^{2}$ yield planted in Wuhan area; $\left(\mathrm{B} \cdot \mathrm{I}_{\mathrm{CE}}\right)$ was $30.943 \mu \mathrm{mol} \cdot \mathrm{S}^{-1} \cdot \mathrm{m}^{-2}$ at the enlongation, and $\mathrm{I}_{\mathrm{CH}}$ was $5.065 \mu \mathrm{mol} \cdot \mathrm{S}^{-1} \cdot \mathrm{m}^{-2}$ at $2550 \mathrm{~kg} / \mathrm{hm}^{2}$ yield planted in Nanjing area.

The percent of the OLAI after end anthesis account for that early anthesis: $\mathrm{b}_{\mathrm{A}}$ was $25 \%$ around at $2400 \mathrm{~kg} / \mathrm{hm}^{2}$ yield planted in Wuhan area; $\mathrm{b}_{\mathrm{A}}$ was $20 \%$ around at $2550 \mathrm{~kg} / \mathrm{hm}^{2}$ yield planted in Nanjing area.

\subsection{The cases of model verification}

The OLAI for "zhongshuang 9" planted in Wuhan and "Ningyou 16" in Nanjing area were simulated, which were compared with the observed values at the corresponding sites and yielding levers(Fig.1 and 2) using meteorological data(the monthly average temperature, the monthly average maximum temperature, the monthly average minimum temperature, the monthly average precipitation, the monthly average rain days, as well as latitude) from Wuhan and Nanjing area, and the corresponding cultivar parameters.

The average absolute deviation $\left(d_{e}\right)$, correlation coefficients $(r)$ and the standard errors of their absolute deviation $\left(S_{d e}\right)$ of the observed(Over-year 1.5, Enlongation 2.0, Early anthesis 4.75, End anthesis 1.18) and simulated values for the OLAI for "zhongshuang 9" in Wuhan were $-0.03,0.9707$ and 0.4032 , respectively, and $r$ was significant at 0.05 level(Fig. 1).
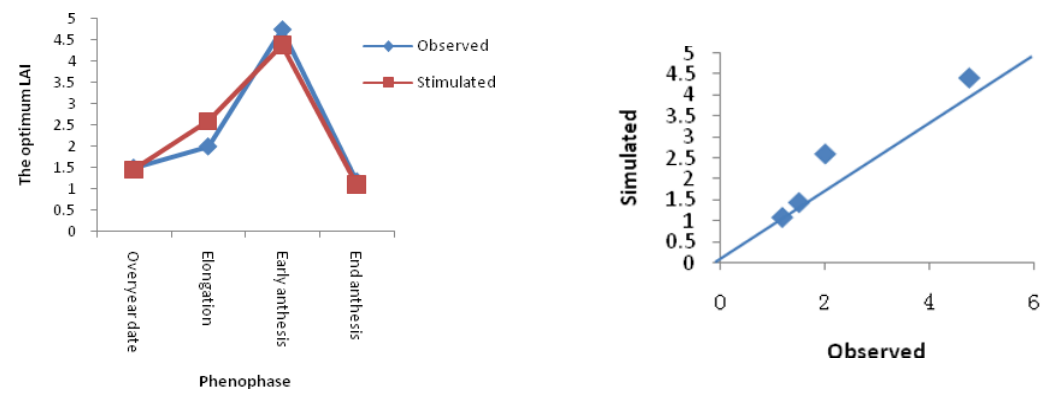

Fig. 1 Comparison of the observed and the stimulated of the OLAI in Wuhan area at 2400 $\mathrm{kg} \cdot \mathrm{hm}^{-2}$ yield for Zhongshuang 9 
The average absolute deviation $\left(d_{e}\right)$, correlation coefficients $(r)$ and the standard errors of their absolute deviation $\left(S_{d e}\right)$ of the observed(Over-year 2.04, Early anthesis 5.9, Yellow mature 1.02) and simulated values for the OLAI for "Ningyou 16" in Nanjing were 0.1533, 0.9997 and 0.1332, respectively, and $r$ was significant at 0.05 level( $\left.\mathrm{r}_{0.05(1)}=0.997\right)($ Fig.2).
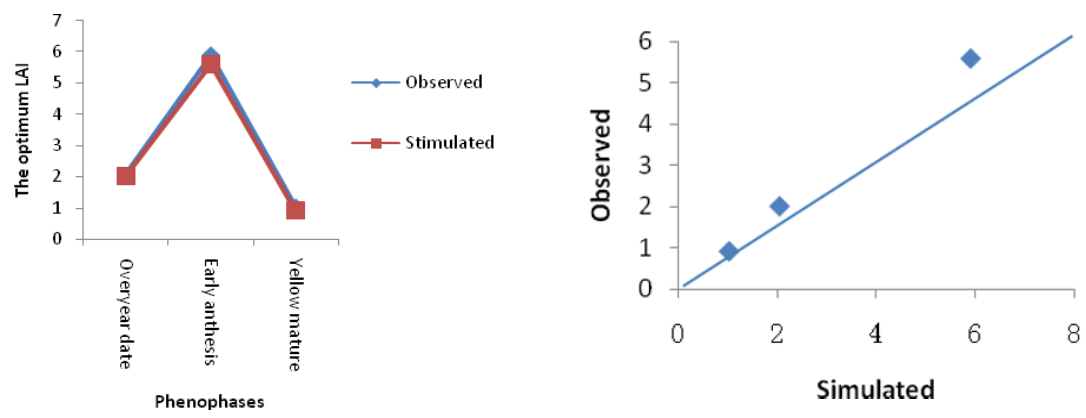

Fig.2 Comparison of the observed and the stimulated of the OLAI in Nanjing area at 2550 $\mathrm{kg} \cdot \mathrm{hm}^{-2}$ yield for Ningyou 16

\section{CONCLUSIONS AND DISCUSSION}

The conventional methods of deciding OLAI in rape cultivation were that the OLAI at various phenophase under different areas, cultivars and yielding levels were obtained by researches of the relationship between LAI and yielding formation, which had important roles in directing rape cultivation with high-yielding, good quality and high benefit. However, the method lacked of widely utility. This paper developed the OLAIDM according to the principle of high-yielding cultivation and optimization and the definition of OLAI, which taken in account multi-factors such as cultivars and light, etc., can estimate the OLAI dynamic with universal suitability, objective, mechanism and dynamic aimed at different areas, cultivars, and yielding levels.

The key factors to assure the OLAI at rape various phenophase under different areas, cultivars and yielding levels can be found out theoretically through analysis of models developed in this paper. e.g., the area with high solar radiation rate and large difference in temperature between day and night had larger OLAI dynamic, and in the same area, the OLAI dynamic could generally had close range when they had the same yielding levels, which had a slightly change in different cultivars. But the OLAI dynamic were clearly different in the same area with different yielding levels. 
The OLAIDM had mechanism of physiology and biology and the principles of feedback controlling for yielding levels. But the verification data were less, which showed that the models developed in this paper needed more verification and continuous perfection.

\section{ACKNOWLEDGEMENTS}

The authors would like to express their appreciation to Prof. Dr. Cunkou Qi and deputy Prof. Xinjun Chen from Economic Crop Institute of Jiangsu Academy of Agricultural Sciences for helping of field experiments in this work, and for funding of national projects in the tenth five-year plan( 2001BA507A-09-04), 948 projects of Agricultural Ministry of China(2004- Z 30), and Jiangsu Province projects(06-G-169)

\section{REFERENCES}

Cao H X, Zhang C L, Jin Z Q, Shi C L, Ge D K, et al. Discussing of Frame and Technological Systems for Digital Cultivation. J Farming and Cultivation, 2005, (3) :4-7

Cao H X, Zhang C L, Li G M, Zhang B J, Zhao S L, Wang B Q, Jin Z Q. Researches of simulation models of rape(Brassica napus L.) growth and development. Acta Agron Sin, 2006,32(10):1530-1536

Farré M J, Robertson G H, Walton S, Asseng. Simulating response of canola to sowing data in Western Australia. In: Hobart Proceedings of the 10th Australia Agron Conference, 2001. pp36- 40

Gabrielle B, Denoroy P, Gosse G, Justes E, Andersen M N. Development and evaluation of a CERES-type model for winter oilseed rape. Field Crop Res, 1998, 57(1):95-111

Gao L Z, Jin Z Q, Huang Y, Li B B, Chen H. Rice Cultivational Simulation-optimizationdecision Making System. Beijing: Chinese Agri Sci \& Tech Press, 1992. pp21-40 (in Chinese)

Gao L Z, Jin Z Q, Zheng G Q, Feng LP, Zhang LZ, Shi CL, Ge D K. Wheat cultivational simulation-optimization-decision making system, J Jiangsu Agric, 2000, 16 (2): 65-72 (in Chinese with English abstract)

Guan C Y. Cultivational Techniques of Good Quality and High Yielding for Rape. Changsha: Hunan Sci \& Tech Press, 1992. (in Chinese)

Habekott B.é. A model of the penological development of winter oilseed rape (Brassica napus L.). Field Crop Res, 1997, 54:137-153.

Hu L Y, Liu T M, Zheng X L, Cao C G, Cao W X, Yan M C. A mechanistic of phasic and phenological development in rape. II. Verification and evaluation of the model. Chin J of Oil Crop Sci , 2004, 26(2):51—54 (in Chinese with English abstract)

Husson F, Wallach D, Vandeputte A. Evaluation of CECOL, a model of winter rape (Brassica napus L.). Europe J of Agron, 1997, 18: 205-214

Kiniry J R, Major.D J, Izaurralde R C, Williams J R, Gassman P W, Morrison M, Bergentine R, Zentener R P. EPIC model parameters for cereal, oilseed, and forage crop in the north Great Plain region. Can J Plant Sci, 1983，63:1063-1065 
Liao G P, Guan C Y,Wu Q Y, Li A P, Chen S Y, Wang G H. Development of knowledgebase of the expert system for rapeseed production. Crop Res,2002, (3) :118-121 (in Chinese with English abstract)

Liao G P, Guan C Y. Study on characteristics of dry matter accumulation, distribution and transfer of winter rapeseed (Brassica napus). Acta Agron Sin, 2002,28(1):52-58 (in Chinese with English abstract).

Ling Q H. Crop population quality, 1st ed. Shanghai: Shanghai Sci and Tech Press, 2000. 217-286(in Chinese)

Liu H L. Rape Culture Science for Application. 1st ed. Shanghai: Shanghai Sci \& Tech Press, 1987. pp220-221 (in Chinese)

Liu H, Jin Z-Q. The simulation models of rape development dynamic. J of Appl Meteo, 2003, (5):634-639 (in Chinese with English abstract)

Liu T-M, Hu L-Y, Zhao Z-H, Cao C-G, Cao W-X, Yan M-C. A echanistic of phasic and phenological development in rape. I. Description of the model. Chin J of Oil Crop Sci, 2004, 26(1): 27-30 (in Chinese with English abstract)

Petersen C T, Svendsen H, Hansen S, Jensen H E, Nieksen N E. Parameter assessment for simulation of biomass production and nitrogen uptake in winter rape. Europe J of Agron, 1995, (4):77-89

Wang Y R. Population Physiology of Crop High-yielding, 1st ed. Beijing: Sci. and Tech. literature Pub. House, China.1991.(in Chinese)

Zhu Y, Cao W X, Shen W X,Tian Y C. A dynamic knowledge model for fertilization management in rapeseed. Chin J Eco, 2005 ,24 (2) :209 213 